\title{
Maternal Diet During Pregnancy and Blood Cadmium Concentrations in an Observational Cohort of British Women
}

\author{
Caroline M. Taylor ${ }^{1, * \mathbb{C}}$, Rita Doerner ${ }^{2}$, Kate Northstone ${ }^{2}$ and Katarzyna Kordas ${ }^{3}$ \\ 1 Centre for Academic Child Health, Bristol Medical School, University of Bristol, 1-5 Whiteladies Road, \\ Bristol BS8 2NU, UK \\ 2 Population Health Sciences, Bristol Medical School, University of Bristol, Oakfield Grove, \\ Bristol BS8 2BN, UK; rita.doerner@charite.de (R.D.); kate.northstone@bristol.ac.uk (K.N.) \\ 3 Department of Epidemiology and Environmental Health, School of Public Health and Health Professions, \\ University at Buffalo, Buffalo, NY 14214, USA; kkordas@buffalo.edu \\ * Correspondence: Caroline.m.taylor@bristol.ac.uk; Tel.: +44(0)117-428-3099
}

Received: 5 March 2020; Accepted: 21 March 2020; Published: 26 March 2020

\begin{abstract}
Few studies have investigated the extent to which diet predicts body $\mathrm{Cd}$ concentrations among women of reproductive age, and pregnant women in particular. The aim of this study was to examine diet as a predictor of blood Cd concentrations in pregnant women participating in the UK Avon Longitudinal Study of Parents and Children (ALSPAC). Whole blood samples were analysed for $\mathrm{Cd}$ (median 0.26 (IQR 0.14-0.54) $\mu \mathrm{g} / \mathrm{L}$ ). Dietary pattern scores were derived from principal components analysis of data from a food frequency questionnaire. Associations between dietary pattern scores and foods/food groups with blood $\mathrm{Cd} \geq$ median value were identified using adjusted logistic regression ( $n=2169$ complete cases). A health conscious dietary pattern was associated with a reduced likelihood of B-Cd $\geq 0.26 \mu \mathrm{g} / \mathrm{l}$ (OR 0.56 (95\% CI 0.39-0.81)). There were similarly reduced likelihoods for all leafy green and green vegetables ( $0.72(0.56-0.92)$ when consumed $\geq 4$ times/week vs $\leq 1$ to $\geq 3$ times/week) and with all meats ( $0.66(0.46-0.95)$ when consumed $\geq 4$ times/week vs $\leq$ once in 2 weeks). Sensitivity analysis excluding smokers showed similar results. The evidence from this study provides continued support for a healthy and varied diet in pregnancy, incorporating foods from all food groups in accordance with national recommendations, without the need for specific guidance.
\end{abstract}

Keywords: ALSPAC; diet; dietary patterns; blood cadmium; pregnancy

\section{Introduction}

Metal contaminants may be incorporated into edible plants during cultivation or settle on plant surfaces at any time during food production, transport, or processing, thus contributing to human exposure [1,2]. Food is the main source of cadmium (Cd) exposure in non-smoking populations [3], and this is particularly concerning in vulnerable groups, such as pregnant women. There are no known safety thresholds for metal exposure and no recommendations for acceptable blood or urine $\mathrm{Cd}$ concentrations specifically during pregnancy [4]. Estimated intestinal absorption ranges from $1 \%$ to $11 \%$ [5] but are thought to increase during pregnancy, at least in laboratory animals [6]. Cd accumulates in the placenta [7] and is detectable in cord blood and plasma, albeit at lower concentrations than in the pregnant woman's blood [8-10]. Nevertheless, maternal Cd exposure has been linked with adverse pregnancy outcomes, including lower birth weight $[7,11,12]$.

The World Health Organization [13] lists Cd among its priority contaminants for monitoring in total diet studies. Across several studies, risk of exposure from dietary sources has been found to be generally low, but some foods, such as vegetables (particularly mushrooms), rice, seafood (particularly 
bivalves), products made with cacao beans, and offal, have particularly high Cd concentrations [14-20], although foods that are more frequently eaten are likely to make the greatest overall contribution to dietary Cd exposure [21]. There is some evidence that food consumption patterns may influence the contribution of the diet to daily $\mathrm{Cd}$ exposure. For example, among 50-79-year-old women participating in the US Women's Health Initiative, higher consumption of vegetables and grains was associated with higher dietary $\mathrm{Cd}$ exposure [22]. Among pregnant women from Mexico, the urinary $\mathrm{Cd}$ concentration measured during the third trimester was positively associated with estimated $\mathrm{Cd}$ in the diet but only among non-smokers [23]. A further study, however, found no associations between a range of food items and blood Cd concentrations (B-Cd) in premenopausal women in the USA [24].

Relative absorption of $\mathrm{Cd}$ can be affected by a number of factors. $\mathrm{Cd}$ typically occurs as a divalent element and can be absorbed via several intestinal transporters. Chief among these is the divalent metal transporter-1 (DMT1), typically responsible for the absorption of iron [18,25]. In pregnant rats, the upregulation of DMT1 in the latter part of pregnancy is the most likely explanation for higher Cd absorption and at least twofold higher $\mathrm{Cd}$ accumulation in the intestine, liver, and kidney compared with non-pregnant controls [6]. Low iron status, which induces DMT1 expression, has been associated with higher blood $\mathrm{Cd}$ concentrations in both pregnant and non-pregnant women of reproductive age who were non-smokers [26-28]. In smokers, concentrations of serum ferritin (a biomarker of iron stores) were inversely associated with B-Cd only among women who were relatively light smokers $(<5$ cigarettes/day) [29].

$\mathrm{Cd}$ in plant foods, however, occurs in complexes with nutrients or bioactive components, which may also affect the absorption of $\mathrm{Cd}$ from the diet [30]. For example, divalent metals may counteract the absorption of $\mathrm{Cd}$ in the intestinal tract or promote the excretion of $\mathrm{Cd}$ [31]. Among US adults aged 20 years or older, total dietary zinc intake (from diet and supplements) was negatively associated with both blood and urinary $\mathrm{Cd}$ concentrations, even when dietary calcium and iron intakes were also considered [32]. Conversely, diets marginal in iron, calcium, and zinc were related to higher intestinal absorption ( $40 \%$ vs. $20 \%$ in controls) and tissue retention of Cd in experimental animals [33], although it is unclear whether this was due to the low nutrient content of the diet or to nutritional deficiencies that result from long-term consumption of nutrient-poor diets.

A number of studies have estimated the potential exposure to $\mathrm{Cd}$ from the total diet and specific foods; however, there is little understanding of how the typical diet is related to $\mathrm{Cd}$ concentrations in blood or urine. Few studies have investigated the extent to which dietary intakes predict body $\mathrm{Cd}$ concentrations among women of reproductive age, and pregnant women in particular. The aim of this study was to examine diet (food groups and dietary patterns) as a predictor of B-Cd in pregnant women participating in the UK Avon Longitudinal Study of Parents and Children (ALSPAC).

\section{Materials and Methods}

\subsection{The ALSPAC Study}

The sample was derived from ALSPAC, a population-based study investigating environmental and genetic influences on the health, behaviour, and development of children. This database includes a large number of participants and a wide range of social and demographic information to enable the most appropriate selection of covariates. All pregnant women in the former Avon Health Authority with an expected delivery date between 1 April 1991 and 31 December 1992 were eligible for the study. In total, 14,541 pregnant women were enrolled. The social and demographic characteristics of this cohort were similar to those found in UK national census surveys [34,35]. Further details of ALSPAC are found at [36]. The study website contains details of all the data that are available through a fully searchable data dictionary and variable search tool [37]. Ethics approval for the study was obtained from the ALSPAC Ethics and Law Committee and the Local Research Ethics Committees. Informed consent for the use of data collected via questionnaires and clinics was obtained from participants following the recommendations of the ALSPAC Ethics and Law Committee at the time. 


\subsection{Exposures}

\subsubsection{Food Frequency Questionnaires}

The dietary intakes were collected from a food frequency questionnaire (FFQ) sent to the ALSPAC mothers at 32 weeks' gestation. The FFQ asked about the current frequency of consumption of 43 different foods and drinks. Possible answers were: (i) never or rarely; (ii) once in 2 weeks; (iii) one to three times per week; (iv) four to seven times per week; (v) more than once per day. This FFQ has been shown to produce mean nutrient intakes [38] similar to those obtained for women in the UK National Diet and Nutritional Survey for adults [39]. The specific question on the frequency of oily fish consumption has also been validated by comparison with the erythrocyte fatty acid composition of pregnancy blood samples: the erythrocyte docosahexaenoic acid (DHA) content increased significantly with an increasing frequency of consumption of oily fish $(p<0.001)$ [40].

\subsubsection{Food Groups}

We combined individual foods of interest into 11 food groups: (1) meats; (2) fish; (3) pulses; (4) nuts; (5) soya bean products; (6) root vegetables; (7) leafy greens and green vegetables; (8) breads and cereals; (9) cakes and biscuits; (10) pastas and rice; (11) pies/pastries. The combinations of foods are described in Table S1. According to the originally reported frequency of consumption per type of food (categories $\mathrm{i}-\mathrm{v}$, above), mothers were then allocated to frequency categories for the new combined food groups, using the original categories provided as part of the FFQ. When consumption varied by food type, mothers were allocated to the subcategory representing the most frequent consumption. For example, within "meats" where a mother reported the consumption of poultry to be "one to three times per week" and red meat to be "never or rarely", she would be assigned to "one to three times per week" for the combined "meats" group.

\subsubsection{Dietary Patterns}

Principal components analysis (PCA) was used to derive underlying dietary patterns in this population. This has been described in detail elsewhere [41]. Briefly, the number of components best representing the data was chosen on the basis of a scree plot and the interpretability of the patterns. A component score was created for each woman for each of the components identified, calculated by multiplying the factor loadings by the corresponding standardised value for each food and summing across the food items (see Northstone, Emmett, and Rogers [41] for factor loadings and variance explained). Each score has a mean of 0 and a higher score indicates closer adherence to that dietary pattern. Five components were obtained: 'health conscious' (high factor loadings for salad, fruit, rice, pasta, oat and bran-based breakfast cereals, fish, pulses, fruit juices, and non-white bread); 'traditional' (high consumption of all types of vegetables and red meat and poultry); 'processed' (high intakes of high-fat processed foods, such as meat pies, sausages and burgers, fried foods, pizza, chips, and baked beans); 'confectionery' (high intakes of foods with high sugar content, such as chocolate, sweets, biscuits, cakes, and other puddings), and 'vegetarian' (high loadings for meat substitutes, pulses, nuts, and herbal teas, and high negative loadings for red meat and poultry).

\subsection{Outcomes}

\subsubsection{Collection, Storage, and Analysis of Blood Samples}

Whole blood samples were collected in acid-washed vacutainers (Becton and Dickinson, Oxford, UK) by midwives as early as possible in pregnancy (median of 11 weeks' gestation (IQR 9-13 weeks) with a mode of 10 weeks). Whole blood samples were stored in the original tube at $4{ }^{\circ} \mathrm{C}$ at the collection site before being transferred to the central Bristol laboratory within 1-4 days. Samples were at ambient temperature during transfer (up to $3 \mathrm{~h}$ ). They were then stored at $4{ }^{\circ} \mathrm{C}$ until analysis. Details of the analysis have been reported previously [42]. In brief, inductively coupled plasma mass spectrometry 
in standard mode (R. Jones, Centers for Disease Control and Prevention (CDC), Bethesda, MD, USA; CDC Method 3009.1) was used to measure B-Cd with appropriate quality controls. The analyses were completed for 4286 women. In total, 1119 samples had a $\mathrm{Cd}$ concentration below the limit of detection (LOD) $(0.20 \mu \mathrm{g} / \mathrm{L})$ : these were assigned a value of $0.14 \mu \mathrm{g} / \mathrm{L}(\mathrm{LOD} / \sqrt{ } 2)$ to reflect the log-normal distribution $[43,44]$. In total, 4211 women with B-Cd data also had data on gestational age at the time of sampling.

\subsubsection{Potential Confounders}

Potential confounding factors were defined a priori from the literature and included measures of socio-economic positioning (SEP), body mass index (BMI), estimated energy intake, lifestyle indicators (alcohol consumption and smoking status before and during pregnancy), and haemoglobin concentrations. Indicators of SEP were: age at pregnancy (categorised as $\leq 19,20-24,25-29$, 30-34, $\geq 35$ years), highest level of educational attainment (none/Certificate of School Education, vocational/Ordinary level, Advanced level and above), and Townsend score, a measure of material deprivation based on geographical area, incorporating census-based data on unemployment, non-car ownership, non-home ownership, and household overcrowding (quartiles from least deprived to most deprived) [45]. Data on BMI (based on height and pre-pregnancy weight), smoking status (yes/no), and alcohol consumption (yes/no) during the first trimester and smoking status pre-pregnancy (yes/no) were obtained from questionnaires completed during pregnancy. Energy intake was estimated from the FFQ at 32 weeks' gestation [46]. Haemoglobin concentrations were extracted from obstetric clinic records (the first recorded concentration was used to correspond with the gestational time of the blood sample for Cd analysis).

\subsection{Statistical Analysis}

Statistical analysis was conducted using STATA version 14.2 (StataCorp, College Station, TX, USA).

We initially examined potential response bias in the sample by comparing mothers who completed the FFQ and had available data on B-Cd with those who did not. The associations between B-Cd and background characteristics were examined.

Continuous B-Cd results were transformed into a binary outcome variable by splitting the sample at the statistical median of $0.26 \mu \mathrm{g} / \mathrm{L}$ to address the skewed nature of the data. Univariable and multivariable logistic regression modelling were used to examine the likelihood of having $\mathrm{B}-\mathrm{Cd} \geq$ median of $0.26 \mu \mathrm{g} / \mathrm{L}$ in cases with complete exposure, outcome, and confounder data only. Two sets of models were produced, whereby one set included the dietary pattern scores as separate predictors, and a second set, the individual food groups. Dietary pattern scores and food groups were not mutually adjusted for. A number of potential confounders were considered in the adjusted models: indicators of SEP, BMI, energy intake, smoking status in the first trimester and alcohol consumption, and haemoglobin concentrations. There was a decline in the prevalence of smoking of 7.6 percentage points from pre-pregnancy to the first trimester (prevalence of smoking in the first trimester was $22.2 \%$ ). B-Cd largely reflects recent exposure (previous 2-3 months) although it may also include a contribution from longer term exposure [47]: as the blood samples were obtained at a median of 11 weeks, only smoking in the first trimester (which broadly represents the previous 2-3 months) was used as a confounder in the main adjusted analyses. Results are reported as unadjusted and adjusted odds ratios (OR) with $95 \%$ confidence intervals $(\mathrm{CI})$.

\subsection{Sensitivity Analyses}

We also conducted three sensitivity analyses by repeating all descriptive statistics as well as logistic regression modelling on subsets of the complete case sample: (1) only mothers who did not smoke in the first trimester; (2) only mothers who did not smoke in the first trimester and did not smoke immediately before becoming pregnancy; and (3) only mothers with B-Cd $\geq$ LOD. 


\section{Results}

\subsection{Diet and Blood Cd Concentrations in Pregnant Women in the Main Analysis (Overall Sample)}

The derivation of the sample included in the analysis of this study is summarised in the flow chart (Figure 1). Table 1 summarises the included and excluded sample in terms of sociodemographic and lifestyle characteristics. Compared with excluded participants, those included in the analysis were more likely to be older, have higher educational attainment, live in less deprived geographical areas as indicated by the Townsend score, and were less likely to be smokers in the first trimester.

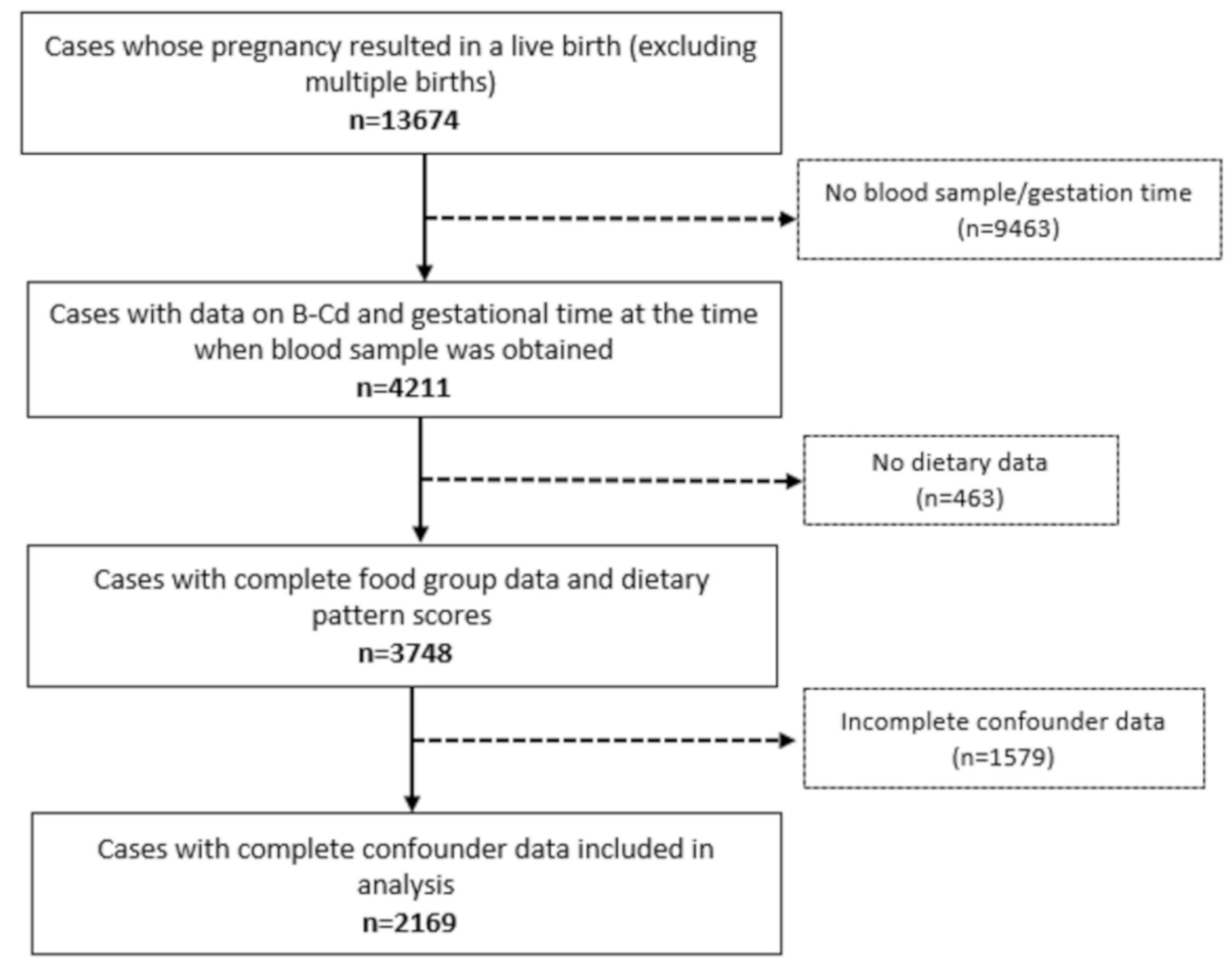

Figure 1. Flow chart for selection of participants from the UK ALSPAC cohort.

Table 1. Included vs. excluded sample comparison: pregnant women enrolled in ALSPAC with complete exposure, outcome, and confounder data $(n=2169)$ by indicators of socioeconomic positioning and other background characteristics compared with the rest of the ALSPAC cohort vs. excluded sample.

\begin{tabular}{lcccc}
\hline \multirow{2}{*}{ Participant Characteristic } & \multicolumn{2}{c}{$\mathbf{n ~ ( \% )}$} & \multirow{2}{*}{ Odds Ratio (95\% CI) } & $p$ Value \\
\cline { 2 - 3 } & Excluded & Included & & \\
\hline \\
$\begin{array}{l}\text { Maternal age at pregnancy (years) } \\
\leq 19\end{array}$ & $600(5.2)$ & $53(2.4)$ & 1.00 & \\
20 to $<25$ & $2341(20.4)$ & $313(14.4)$ & $1.51(1.11,2.05)$ & \\
25 to $<30$ & $4437(38.6)$ & $850(39.2)$ & $2.17(1.62,2.90)$ & \\
30 to $<35$ & $3014(26.2)$ & $709(32.8)$ & $2.67(1.80,3.58)$ & $<0.001$ \\
$\geq 35$ & $1113(9.7)$ & $242(11.2)$ & $2.46(1.80,3.37)$ & \\
Maternal education & & & & \\
$\quad$ None/CSE & $3104(31.1)$ & $541(24.9)$ & 1.00 & $<0.001$ \\
$\quad$ Vocational/O-level & $5672(56.9)$ & $1262(58.2)$ & $1.27(1.14,1.42)$ & \\
$\quad$ A-level and above & $1191(12.0)$ & $366(16.9)$ & $1.76(1.52,2.05)$ & \\
\hline
\end{tabular}


Table 1. Cont.

\begin{tabular}{|c|c|c|c|c|}
\hline \multirow{2}{*}{ Participant Characteristic } & \multicolumn{2}{|c|}{ n $(\%)$} & \multirow{2}{*}{ Odds Ratio (95\% CI) } & \multirow{2}{*}{$p$ Value } \\
\hline & Excluded & Included & & \\
\hline \multicolumn{5}{|l|}{ Maternal social class } \\
\hline $\mathrm{I} / \mathrm{II}$ & $2936(36.9)$ & $734(39.2)$ & 1.00 & \\
\hline III non-manual/III manual & $4041(50.8)$ & $936(50.0)$ & $0.93(0.83,1.03)$ & \\
\hline $\mathrm{IV} / \mathrm{V}$ & $982(12.3)$ & $203(10.8)$ & $0.83(0.70,0.98)$ & 0.074 \\
\hline \multicolumn{5}{|l|}{ Paternal social class } \\
\hline \multicolumn{5}{|l|}{ Total $n$} \\
\hline $\mathrm{I} / \mathrm{II}$ & $3850(44.3)$ & $964(48.3)$ & 1.00 & \\
\hline III non-manual/III manual & $3733(42.9)$ & $795(39.8)$ & $0.85(0.77,0.94)$ & \\
\hline $\mathrm{IV} / \mathrm{V}$ & $1115(12.8)$ & $239(12.0)$ & $0.86(0.73,1.00)$ & 0.055 \\
\hline \multicolumn{5}{|l|}{ Townsend score } \\
\hline 1 & $2347(32.5)$ & $658(30.3)$ & 1.00 & \\
\hline 2 & $1398(19.4)$ & $341(15.7)$ & $0.87(0.75,1.01)$ & \\
\hline 3 & 1907 (26.44) & $578(26.7)$ & $1.08(0.95,1.23)$ & \\
\hline 4 & $1560(21.63)$ & $592(27.3)$ & $1.35(1.19,1.54)$ & $<0.001$ \\
\hline \multicolumn{5}{|l|}{ Smoking status in 1st trimester } \\
\hline No & $7973(74.4)$ & $1687(77.8)$ & 1.00 & \\
\hline Yes & $2737(25.6)$ & $482(22.2)$ & $0.83(0.75,0.93)$ & 0.001 \\
\hline \multicolumn{5}{|l|}{ Maternal dietary scores } \\
\hline Health conscious & $-0.022 \pm 1.004$ & $0.100 \pm 0.975$ & & $<0.001$ \\
\hline Traditional & $-0.002 \pm 1.006$ & $0.009 \pm 0.217$ & & 0.531 \\
\hline Processed & $0.013 \pm 1.012$ & $-0.056 \pm 0.942$ & & 0.006 \\
\hline Confectionery & $0.006 \pm 1.009$ & $-0.022 \pm 0.960$ & & 0.200 \\
\hline Vegetarian & $-0.003 \pm 0.994$ & $0.010 \pm 1.028$ & & 0.643 \\
\hline
\end{tabular}

Educational attainment: none/Certificate of School Education, vocational/Ordinary level, Advanced level and above. Townsend score is a measure of deprivation: 1 is the least deprived, score 4 the most deprived [45]. Social class: I, higher managerial, administrative or professional; II, intermediate managerial, administrative or professional; III non-manual, supervisory or clerical and junior management, administrative or professional; III manual, skilled manual workers; IV, semi-skilled and unskilled manual workers; V, casual or lowest grade workers

The mean B-Cd concentration was 0.50 (SD 0.58), range 0.14-6.30, with a median value of 0.26 (IQR 0.14-0.54) $\mu \mathrm{g} / \mathrm{L}$, but 664 (31\%) women had values below the LOD. The mean value for 'never vegetarian' was 0.50 (SD 0.58), 'vegetarian in the past' 0.57 (SD 0.66), and 'presently vegetarian' 0.42 (SD 0.41) $\mu \mathrm{g} / \mathrm{L}$ ( $p=0.384$ for 'never vegetarian' vs. 'presently vegetarian').

Participant characteristics according to the B-Cd category ( $<$ median or $\geq$ median) are shown in Table 2. Compared with participants with B-Cd $<$ median, those with B-Cd $\geq$ median were more likely to be younger, have lower educational attainment, reside in more deprived geographical areas (Townsend score), and be smokers. 
Table 2. Blood cadmium concentrations in pregnant women enrolled in ALSPAC by indicators of socio-economic positioning and lifestyle (complete case analysis including smokers, $n=2169$ ).

\begin{tabular}{|c|c|c|c|c|c|}
\hline \multirow[b]{2}{*}{ Variable } & \multirow{2}{*}{$\begin{array}{l}\text { Included Sample } \\
\text { Observations } n \\
(\%)\end{array}$} & \multicolumn{2}{|c|}{$n(\%)$} & \multirow{2}{*}{$\begin{array}{c}\text { Odds Ratio } \\
\text { (95\% CI) }\end{array}$} & \multirow[b]{2}{*}{$p$ Value } \\
\hline & & $\begin{array}{l}\text { B-Cd < } \\
\text { Median }\end{array}$ & $\begin{array}{l}\text { B-Cd } \geq \\
\text { Median }\end{array}$ & & \\
\hline \multicolumn{6}{|l|}{ Maternal age (years) } \\
\hline$\leq 19$ & $53(2.4)$ & $15(1.2)$ & $38(3.6)$ & 1.00 & \\
\hline 20 to $<25$ & $313(14.4)$ & $126(10.4)$ & $187(19.5)$ & $0.59(0.3,1.1)$ & \\
\hline 25 to $<30$ & $850(39.2)$ & $480(39.7)$ & $370(38.5)$ & $0.30(0.2,0.6)$ & \\
\hline 30 to $<35$ & $711(32.8)$ & $444(36.7)$ & $267(27.8)$ & $0.24(0.1,0.4)$ & \\
\hline$\geq 35$ & $242(11.7)$ & $144(11.9)$ & $98(10.2)$ & $0.27(0.1,0.5)$ & $<0.001$ \\
\hline \multicolumn{6}{|l|}{ Maternal education } \\
\hline None/CSE & $541(24.9)$ & $231(19.1)$ & $310(32.3)$ & 1.00 & \\
\hline Vocational/O-level & $1262(58.2)$ & $714(59.1)$ & $548(57.1)$ & $0.57(0.5,0.7)$ & \\
\hline A-level and above & $366(16.9)$ & $264(21.8)$ & $102(10.6)$ & $0.29(0.2,0.4)$ & $<0.001$ \\
\hline \multicolumn{6}{|l|}{ Townsend score } \\
\hline 1 & $658(30.3)$ & $420(34.7)$ & $238(24.8)$ & 1.00 & \\
\hline 2 & $341(15.7)$ & $208(17.2)$ & $133(13.9)$ & $1.13(0.9,1.5)$ & \\
\hline 3 & $578(26.7)$ & $315(26.1)$ & $263(27.4)$ & $1.47(1.2,1.9)$ & \\
\hline 4 & $592(27.3)$ & $266(22.0)$ & $326(34.0)$ & $2.16(1.7,2.7)$ & $<0.001$ \\
\hline \multicolumn{6}{|l|}{$\begin{array}{l}\text { Smoking status in 1st } \\
\text { trimester }\end{array}$} \\
\hline No & $1687(77.8)$ & $1188(98.3)$ & $499(52.0)$ & 1.00 & \\
\hline Yes & $482(22.2)$ & $21(1.74)$ & $461(48.0)$ & $52.3(33.3,82.0)$ & $<0.001$ \\
\hline \multicolumn{6}{|l|}{$\begin{array}{l}\text { Smoked regularly } \\
\text { pre-pregnancy }\end{array}$} \\
\hline No & $1522(70.2)$ & $1051(96.5)$ & $471(43.6)$ & 1.00 & $<0.001$ \\
\hline Yes & $647(29.8)$ & $38(0.3)$ & $609(56.4)$ & $28.6(20.7,39.4)$ & \\
\hline \multicolumn{6}{|l|}{ Alcohol consumption } \\
\hline No & $959(44.2)$ & $548(45.3)$ & $411(42.8)$ & 1.00 & \\
\hline Yes & $1210(55.8)$ & $661(54.7)$ & $549(57.2)$ & $1.11(0.9,1.3)$ & 0.241 \\
\hline \multicolumn{6}{|l|}{ BMI } \\
\hline Normal/underweight & $1711(78.9)$ & $967(80.0)$ & $244(77.5)$ & 1.00 & \\
\hline Overweight & $343(15.8)$ & $185(15.3)$ & $158(16.5)$ & $1.11(0.9,1.4)$ & \\
\hline Obese & $115(5.3)$ & $57(4.7)$ & $58(6.04)$ & $1.32(0.9,1.9)$ & 0.268 \\
\hline \multicolumn{6}{|l|}{ Vegetarian diet } \\
\hline Never & $1812(85.3)$ & $1024(86.6)$ & 788 (83.7) & 1.00 & \\
\hline In the past & $180(8.5)$ & $87(7.4)$ & $93(9.9)$ & $1.39(1.0,1.9)$ & \\
\hline Present & $131(6.2)$ & $71(6.0)$ & $60(6.4)$ & $1.10(0.8,1.6)$ & 0.104 \\
\hline
\end{tabular}

Educational attainment: none/Certificate of School Education, vocational/Ordinary level, Advanced level and above. Townsend score is a measure of deprivation: 1 is the least deprived, score 4 the most deprived [45]. Social class: I, higher managerial, administrative or professional; II, intermediate managerial, administrative or professional; III non-manual, supervisory or clerical and junior management, administrative or professional; III manual, skilled manual workers; IV, semi-skilled and unskilled manual workers; V, casual or lowest grade workers. Median B-Cd $0.26 \mu \mathrm{g} / \mathrm{L}$. BMI (body mass index): normal/underweight $<24.9$; overweight $25.0-29.9$; obese $\geq 30.0 \mathrm{~kg} / \mathrm{m}^{2}$.

Only one of the five dietary patterns showed evidence of an association with B-Cd (Table 3). Closer adherence to the health conscious pattern indicated a reduced likelihood of having B-Cd $\geq$ median in the unadjusted model (model 1: OR 0.27 (95\% CI 0.21-0.35) for quartile 4 vs. quartile $1)$ as well as the adjusted model (model 2: $0.56(0.39-0.81)$ ). Women in the highest quartile of the processed pattern had a higher likelihood of having B-Cd $\geq$ median (model 1: 1.99 (1.55-2.54)), but this association was attenuated in the adjusted model (model 2: $1.19(0.84-1.68)$ ). Similarly, having a vegetarian pattern was associated with a greater likelihood of $\mathrm{B}-\mathrm{Cd} \geq$ median (model 1: 1.51 (1.19-1.92) that was attenuated after adjustment $(1.25(0.93-1.68))$. No other dietary patterns were associated with $\mathrm{B}-\mathrm{Cd}$ in the unadjusted or adjusted models. 
Table 3. Associations of dietary patterns with blood cadmium concentrations in pregnant women enrolled in ALSPAC (complete case analysis including smokers, $n=2169$ ).

\begin{tabular}{|c|c|c|c|c|c|c|}
\hline \multirow[b]{2}{*}{ Pattern } & \multirow[b]{2}{*}{ Quartile } & \multirow{2}{*}{$\begin{array}{c}\text { Median } \\
\text { B-Cd }(\mu \mathrm{g} / \mathrm{L})\end{array}$} & \multicolumn{2}{|c|}{$n(\%)$} & \multirow{2}{*}{$\begin{array}{l}\text { Unadjusted } \\
\text { Model } 1\end{array}$} & \multirow{2}{*}{$\begin{array}{c}\text { Adjusted } \\
\text { Model } 2\end{array}$} \\
\hline & & & $\begin{array}{l}\text { B-Cd }< \\
\text { Median }\end{array}$ & $\begin{array}{c}\text { B-Cd } \geq \\
\text { Median }\end{array}$ & & \\
\hline \multirow{5}{*}{$\begin{array}{l}\text { Health } \\
\text { conscious }\end{array}$} & & $\begin{array}{c}\text { Group } \\
\text { median: } 0.26\end{array}$ & & & & \\
\hline & 1 & 0.40 & $173(14.3)$ & 285 (29.7) & 1.00 & 1.00 \\
\hline & 2 & 0.29 & $262(21.7)$ & $260(27.1)$ & $0.60(0.47-0.78)$ & $0.86(0.62-1.18)$ \\
\hline & 3 & 0.25 & $362(29.9)$ & $232(24.2)$ & $0.39(0.30-0.50)$ & $0.69(0.50-0.96)$ \\
\hline & 4 & 0.22 & 412 (34.1) & $183(19.1)$ & $\begin{array}{l}0.27(0.21-0.35) \\
p \text { trend }<0.001\end{array}$ & $\begin{array}{l}0.56(0.39-0.81) \\
p \text { trend }=0.001\end{array}$ \\
\hline \multirow[t]{4}{*}{ Traditional } & 1 & 0.28 & $279(23.1)$ & $254(26.5)$ & 1.00 & 1.00 \\
\hline & 2 & 0.25 & 302 (24.9) & $209(21.8)$ & $0.76(0.600 .97)$ & $0.81(0.60-1.09)$ \\
\hline & 3 & 0.27 & $314(26.0)$ & $252(26.3)$ & $0.88(0.70-1.12)$ & $0.88(0.66-1.18)$ \\
\hline & 4 & 0.26 & $314(26.0)$ & $245(25.5)$ & $\begin{array}{l}0.86(0.68-1.09) \\
p \text { trend }=0.408\end{array}$ & $\begin{array}{l}0.94(0.70-1.27) \\
p \text { trend }=0.903\end{array}$ \\
\hline \multirow[t]{4}{*}{ Processed } & 1 & 0.23 & 362 (29.9) & $205(21.4)$ & 1.00 & 1.00 \\
\hline & 2 & 0.25 & $338(28.0)$ & $231(24.1)$ & $1.21(0.95-1.53)$ & $1.07(0.81-1.43)$ \\
\hline & 3 & 0.29 & $266(22.0)$ & $250(26.0)$ & $1.66(1.30-2.12)$ & $1.46(1.08-1.97)$ \\
\hline & 4 & 0.31 & $243(20.1)$ & $274(28.5)$ & $\begin{array}{l}1.99(1.56-2.54) \\
p \text { trend }<0.001\end{array}$ & $\begin{array}{l}1.19(0.84-1.68) \\
p \text { trend }=0.078\end{array}$ \\
\hline \multirow[t]{4}{*}{ Confectionery } & 1 & 0.28 & $289(24.3)$ & $122(24.5)$ & 1.00 & 1.00 \\
\hline & 2 & 0.26 & $308(25.9)$ & $132(26.5)$ & $0.92(0.731 .16)$ & $1.05(0.79-1.41)$ \\
\hline & 3 & 0.25 & $313(26.4)$ & $130(26.1)$ & $0.81(0.64-1.03)$ & $1.07(0.79-1.45)$ \\
\hline & 4 & 0.27 & $278(23.4)$ & $115(23.1)$ & $\begin{array}{l}0.93(0.73-1.19) \\
p \text { trend }=0.375\end{array}$ & $\begin{array}{l}1.05(0.74-1.48) \\
p \text { trend }=0.844\end{array}$ \\
\hline \multirow[t]{4}{*}{ Vegetarian } & 1 & 0.24 & $365(30.2)$ & $214(22.3)$ & 1.00 & 1.00 \\
\hline & 2 & 0.27 & $303(25.1)$ & $240(25.0)$ & $1.35(1.06-1.72)$ & $1.13(0.85-1.52)$ \\
\hline & 3 & 0.29 & $258(21.3)$ & $255(26.6)$ & $1.69(1.32-2.15)$ & $1.13(0.83-1.53)$ \\
\hline & 4 & 0.28 & $283(23.4)$ & $251(26.2)$ & $\begin{array}{l}1.51(1.19-1.92) \\
p \text { trend }<0.001\end{array}$ & $\begin{array}{l}1.25(0.93-1.68) \\
p \text { trend }=0.132\end{array}$ \\
\hline
\end{tabular}

Model 2 adjusted for maternal age, maternal education, Townsend score, BMI and energy intake, alcohol consumption and smoking status during first trimester, and haemoglobin concentrations.

In the analysis of the food groups (Table 4), two categories were negatively associated with B-Cd in the unadjusted and adjusted models: (1) compared with consumption $\leq 1$ to 3 times per week, eating all leafy greens and green vegetables $\geq 4$ times per week was negatively associated with B-Cd in the unadjusted (model 1: 0.62 (0.51-0.76)) and adjusted (model 2: 0.72 (0.56-0.92)) analyses; (2) compared with all meats $<$ once in 2 weeks, consumption $\geq 4$ times per week was negatively associated with B-Cd in the unadjusted (model 1: $0.62(0.47-0.83)$ ) and adjusted (model 2: $0.66(0.46-0.95)$ ) model. The was a trend for a negative association of increasing all fish consumption with B-Cd. There was evidence of a negative association between the consumption of root vegetables and $\mathrm{B}-\mathrm{Cd}$ in the unadjusted analysis comparing never/rarely vs. $\geq 4$ times per week (model 1: $0.42(0.27-0.65)$ ). However, it was attenuated on adjustment (model 2: $0.77(0.44-1.34)$ ). Similarly, we observed negative associations between B-Cd and bread and cereal, cakes and biscuits, pasta and rice, all pulses, and all nuts in the unadjusted but not in the adjusted models. 
Table 4. Associations of the frequency of intakes of foods and food groups with blood cadmium concentrations in pregnant women enrolled in ALSPAC (complete case analysis including smokers, $n=2169$ ).

\begin{tabular}{|c|c|c|c|c|}
\hline & \multicolumn{2}{|c|}{$n(\%)$} & \multicolumn{2}{|c|}{ OR $(95 \%$ CI $)$} \\
\hline & B-Cd $<$ Median & B-Cd $\geq$ Median & Unadjusted Model 1 & Adjusted Model 2 \\
\hline Total $n$ & 1209 & 960 & & \\
\hline \multicolumn{5}{|l|}{ All meats combined } \\
\hline$\leq$ Once in 2 weeks & $148(12.24)$ & $151(15.73)$ & 1.00 & 1.00 \\
\hline$\leq 3$ times per week & $752(62.20)$ & $613(63.85)$ & $0.80(0.62-1.03)$ & $0.77(0.57-1.04)$ \\
\hline \multirow{2}{*}{$\geq 4$ times per week for at least one group } & $309(25.56)$ & $196(20.42)$ & $0.62(0.47-0.83)$ & $0.66(0.46-0.95)$ \\
\hline & & & $p$ trend $=0.001$ & $p$ trend $=0.021$ \\
\hline \multicolumn{5}{|l|}{ All fish } \\
\hline$\leq$ Once in 2 weeks & $545(45.08)$ & $537(55.94)$ & 1.00 & 1.00 \\
\hline$\geq 1$ to 3 times per week & $614(50.79)$ & $391(40.73)$ & $0.65(0.54-0.77)$ & $0.76(0.61-0.95)$ \\
\hline \multirow{2}{*}{$\geq 4$ to 7 times per week } & $50(4.14)$ & $32(3.33)$ & $0.65(0.41-1.03)$ & $0.82(0.47-1.42)$ \\
\hline & & & $p$ trend $<0.001$ & $p$ trend $=0.026$ \\
\hline \multicolumn{5}{|l|}{ Milk (glasses per day) ${ }^{a}$} \\
\hline None/rarely & $513(43.62)$ & $406(43.80)$ & 1.00 & 1.00 \\
\hline 1 to 2 glasses per day & $473(48.72)$ & $433(46.71)$ & $0.95(0.80-1.14)$ & $0.83(0.66-1.03)$ \\
\hline \multirow[t]{2}{*}{$\geq 3$ glasses per day } & $90(7.65)$ & $88(9.49)$ & $1.24(0.90-1.70)$ & $0.86(0.58-1.29)$ \\
\hline & & & $p$ trend $=0.548$ & $p$ trend $=0.162$ \\
\hline \multicolumn{5}{|l|}{ All pulses combined } \\
\hline$\leq$ Once in 2 weeks & $1.37(11.3)$ & $135(14.1)$ & 1.00 & 1.00 \\
\hline$\leq 3$ times per week & $960(79.4)$ & $750(78.1)$ & $0.79(0.61-1.02)$ & $0.74(0.57-1.00)$ \\
\hline \multirow[t]{2}{*}{$\geq 4$ times per week for at least one group } & $112(9.3)$ & $75(7.8)$ & $0.68(0.47-0.99)$ & $0.71(0.45-1.12)$ \\
\hline & & & $p$ trend $=0.035$ & $p$ trend $=0.105$ \\
\hline \multicolumn{5}{|l|}{ All nuts combined } \\
\hline Never/rarely & $137(11.3)$ & 13514.1 & 1.00 & 1.00 \\
\hline$\leq$ Once in 2 weeks & $960(79.4)$ & 75078.1 & $0.79(0.61-1.02)$ & $0.74(0.54-1.00)$ \\
\hline \multirow{2}{*}{$\geq 1$ to 3 times per week } & $112(9.3)$ & 757.8 & $0.68(0.47-0.99)$ & $0.71(0.45-1.12)$ \\
\hline & & & $p$ trend $=0.009$ & $p$ trend $=0.875$ \\
\hline \multicolumn{5}{|l|}{ Soya bean products } \\
\hline Never or rarely & $1096(90.7)$ & 87090.6 & 1.00 & 1.00 \\
\hline \multirow[t]{2}{*}{$\leq$ Once in 2 weeks } & $113(9.4)$ & 909.4 & $1.00(0.75-1.34)$ & $1.37(0.97-1.92)$ \\
\hline & & & $p$ trend $=0.982$ & $p$ trend $=0.051$ \\
\hline \multicolumn{5}{|l|}{ Root vegetables } \\
\hline Never or rarely & $35(2.9)$ & 565.8 & 1.00 & 1.00 \\
\hline$\leq$ One to 3 times per week per food & $700(57.9)$ & 58861.3 & $0.53(0.34-0.81)$ & $0.70(0.41-1.22)$ \\
\hline \multirow[t]{2}{*}{$\geq 4$ to 7 times per week } & $474(39.2)$ & 31632.9 & $0.42(0.27-0.65)$ & $0.77(0.44-1.34)$ \\
\hline & & & $p$ trend $<0.001$ & $p$ trend $=0.905$ \\
\hline All leafy green and green vegetables & & & & \\
\hline$\leq 1$ to 3 times per week & $236(19.5)$ & 26928.0 & 1.00 & 1.00 \\
\hline$\geq 4$ times per week & $973(80.5)$ & 69172.0 & $0.62(0.51-0.76)$ & $0.72(0.56-0.92)$ \\
\hline & & & $p$ trend $<0.001$ & $p$ trend $=0.005$ \\
\hline Combined breads and cereals & & & & \\
\hline$\leq$ Once a week & $101(8.35)$ & $162(16.88)$ & 1.00 & 1.00 \\
\hline$\leq$ One to 3 times per week per food & $321(26.55)$ & $282(29.38)$ & $0.55(0.41-0.74)$ & $0.76(0.53-1.10)$ \\
\hline$\geq 4$ to 7 times per week & $787(65.10)$ & $516(53.75)$ & $0.41(0.31-0.54)$ & $0.71(0.50-1.01)$ \\
\hline & & & $p$ trend $<0.001$ & $p$ trend $=0.069$ \\
\hline All cakes and biscuits & & & & \\
\hline$\leq$ Once a week & $183(15.14)$ & $205(21.35)$ & 1.00 & 1.00 \\
\hline$\leq$ One to 3 times per week per food & $600(49.63)$ & $471(49.06)$ & $0.70(0.56-0.88)$ & $0.79(0.59-1.06)$ \\
\hline$\geq 4$ to 7 times per week & $426(35.24)$ & $284(29.58)$ & $0.59(0.46-0.76)$ & $0.79(0.57-1.11)$ \\
\hline & & & $p$ trend $<0.001$ & $p$ trend $=0.204$ \\
\hline All pies and pastries & & & & \\
\hline Never or rarely & $245(20.26)$ & $196(20.42)$ & 1.00 & 1.00 \\
\hline$\leq$ Once in 2 weeks & $687(56.82)$ & $511(53.23)$ & $0.93(0.75-1.16)$ & $1.01(0.77-1.32)$ \\
\hline$\geq 1$ to 3 times per week & $277(22.91)$ & $253(26.35)$ & $1.14(0.89-1.47)$ & $0.87(0.62-1.21)$ \\
\hline & & & $p$ trend $=0.254$ & $p$ trend $=0.343$ \\
\hline All pasta and rice & & & & \\
\hline Never or rarely & $89(7.36)$ & 125 (13.02) & 1.00 & 1.00 \\
\hline$\leq$ Once in 2 weeks & $335(27.71)$ & $318(33.13)$ & $0.68(0.49-0.92)$ & $0.84(0.56-1.24)$ \\
\hline$\geq 1$ to 3 times per week & $785(64.93)$ & $517(53.85)$ & $0.47(0.35-0.63)$ & $0.78(0.53-1.15)$ \\
\hline & & & $p$ trend $<0.001$ & $p$ trend $=0.169$ \\
\hline
\end{tabular}


3.2. Sensitivity Analysis 1: Diet and Blood Cd Concentrations in Pregnant Women with Exclusion of Those Who Smoked in the First Trimester

The demographic characteristics of participants who did not smoke in the first trimester by B-Cd were similar to those in the main analysis: compared with participants with B-Cd $<$ median, those with B-Cd $\geq$ median were more likely to be younger, have lower educational attainment, and reside in more deprived geographical areas (Townsend score) (Table S2). When participants who smoked in the first trimester were excluded, the results were broadly similar to those of the whole group. The health conscious dietary pattern again predicted a likelihood of having B-Cd $<$ median in the and adjusted models, but the processed pattern was not associated even in the unadjusted model (Table S3). All meats, all fish, and all leafy green and green vegetables were again associated with a lower likelihood of having B-Cd $\geq$ median in both the unadjusted and adjusted models. Breads and cereals, cakes and biscuits, and pasta and rice consumption were also negatively associated with the likelihood of having higher B-Cd in the unadjusted models but not in the adjusted models (Table S4).

\subsection{Sensitivity Analysis 2: Diet and Blood Cd Concentrations in Pregnant Women with Exclusion of Those Who Smoked in the First Trimester and Pre-Pregnancy}

With the additional exclusion of those who smoked pre-pregnancy, the demographic characteristics of participants by B-Cd showed similar but weaker associations compared with only the exclusion of participants who smoked in the first trimester: Compared with participants with B-Cd $<$ median, those with $\mathrm{B}-\mathrm{Cd} \geq$ median were more likely to be younger and reside in more deprived geographical areas (Townsend score). However, there was no association with lower educational attainment (Table S5). The results of the analyses of the association with dietary patterns and foods/food groups were broadly similar to those of the whole group and the exclusion only of those who smoked in the first trimester: The health conscious dietary pattern again predicted a likelihood of having B-Cd $<$ median in the unadjusted and adjusted models, but there were no other associations (Table S6). Negative associations for all fish were again evident but not for all meat or all leafy green and green vegetables (Table S7).

\subsection{Sensitivity Analysis 3: Diet and Blood Cd Concentrations Among Pregnant Women with Detectable B-Cd}

The demographic characteristics of participants with detectable B-Cd were similar to the those in the complete case analysis and to non-smokers: those with B-Cd $\geq$ median were more likely to be younger, have lower educational attainment, and reside in more deprived geographical areas (Townsend score) (Table S8). Associations with dietary patterns and food/food groups were generally consistent with the main findings. The health conscious pattern was associated with a lower likelihood of $\mathrm{B}-\mathrm{Cd} \geq$ median and the processed pattern with a higher likelihood, but these associations were attenuated on adjustment. The confectionery pattern was associated with a lower likelihood of B-Cd $\geq$ median, whereas the vegetarian pattern was associated with a greater likelihood in both the unadjusted and adjusted models (Table S9). This was not explained by vegetarians being more likely to have B-Cd $>$ LOD (Table S10). All cakes and biscuits and all pies and pastries were associated with a lower likelihood of having $\mathrm{B}-\mathrm{Cd} \geq$ median in both the unadjusted and adjusted models (Table S11).

\section{Discussion}

Diet is an important route of exposure to $\mathrm{Cd}$ in pregnancy for non-smokers, but there has been little work on the dietary predictors of B-Cd in pregnant women. We found that a health conscious dietary pattern was associated with a lower likelihood of $\mathrm{B}-\mathrm{Cd} \geq$ median value in a group of pregnant women in the UK. There was a similarly reduced likelihood of $\mathrm{B}-\mathrm{Cd} \geq$ median value for the food group all leafy green and green vegetables, which appears consistent with the health conscious pattern, and with the food group all meats.

$\mathrm{Cd}$ is a persistent environmental pollutant that is readily incorporated into plant tissues during cultivation [30], and hence into meat and meat products and into dairy foods by bioaccumulation. Foods and food products can also be subject to external contamination (from dust, for example) during 
growth and processing [1,2]. Following exposure through food consumption and from other sources, $\mathrm{Cd}$ accumulates in all tissues, with the greatest concentrations in the liver and kidney [30]. The overall half-life is $>26$ years, with excretion through faeces and urine [5]. In pregnancy, the placenta acts as a partial barrier to $\mathrm{Cd}[10,48]$.

The most frequently used biomarkers for $\mathrm{Cd}$ exposure are whole blood or urine concentrations. B-Cd primarily indicates short-term exposure over 2-3 months at low to moderate exposures; urine concentration reflects longer-term Cd storage, particularly in the kidney [49]. Exposure to Cd was measured as B-Cd in this study: the concentration in this population (for complete cases: median 0.26 (IQR 0.14-0.54), mean 0.50 (SD 0.58), and geometric mean $0.33 \mu \mathrm{g} / \mathrm{L}$ ) was similar to recent concentrations from pregnant women in similar developed countries [4] (for example, USA: geometric mean 0.18 $\mu \mathrm{g} / \mathrm{L}$; Sweden: mean $0.30 \mu \mathrm{g} / \mathrm{L}$ ) [50,51]. Cigarette smoking is the main non-dietary predictor of B-Cd in populations not exposed through occupation [52]. Disparities in blood concentrations between cohorts may therefore indicate differences in smoking prevalence as well as differences in dietary intakes. Cohorts in which the prevalence of smoking is high tend to have high B-Cd. For example, in a French cohort in which $28 \%$ of women smoked during pregnancy and $30 \%$ experienced passive smoking, the median B-Cd was 0.8 (IQR 0.1-4.6) $\mu \mathrm{g} / \mathrm{L}$ [53]. There are no national or international guidelines for maximum B-Cd specifically for pregnancy to our knowledge. The German Human Biomonitoring Commission for all non-smoking adults indicates a population reference value of $1 \mu \mathrm{g} / \mathrm{L}$ [54]. In total, $98 \%$ of our non-smoking complete case sample were below this concentration. In our sample, the relative contribution of foods and food groups to B-Cd was similar in smokers and non-smokers: upon excluding smokers from our cohort (22\% of sample with complete data), we found broadly similar results for the associations of dietary patterns, foods, and food groups with B-Cd to those in the whole sample.

The mean dietary intake of $\mathrm{Cd}$ in the UK has been estimated at 1.54 (95\% CI 1.49-1.54) $\mu \mathrm{g} / \mathrm{per} \mathrm{kg}$ body weight per week, with $17.1 \%$ (95\% CI 15.8-18.5) of individuals estimated to exceed the European Food Standards Agency's current tolerable weekly intake of $2.5 \mu \mathrm{g} / \mathrm{kg}$ body weight per week [55]. Rice, bread and cereals, leafy vegetables, and some roots and tubers (carrots and potatoes) are relatively high in Cd on a weight for weight basis in the UK [56], and in the USA, cereals/bread, leafy vegetables and potatoes were the top three foods/food groups contributing to dietary Cd intake [57]. Potatoes were identified as having a high median Cd concentration in northern Italy $(10.5 \mu \mathrm{g} / \mathrm{kg})$ [58], and in Bangladesh, leafy green vegetables have been reported as having even higher Cd concentrations than root vegetables [20]. In contrast, we found that greater all leafy green and green vegetables consumption was associated with lower B-Cd, as was following a health conscious dietary pattern rich in plant-based foods, and there was no association with root vegetable intake. It is possible that the high levels of dietary fibre provided by the health conscious dietary pattern could reduce the relative absorption of $\mathrm{Cd}$ though a faster gut transit time, or possibly by changes in the gut microbiome. However, in assessing the contribution to overall dietary exposure to $\mathrm{Cd}$, it is important to consider not only absolute concentrations but also the frequency of consumption and portion sizes. For example, for potatoes containing $10.5 \mu \mathrm{g} \mathrm{Cd} / \mathrm{kg}$, an average portion size of $175 \mathrm{~g}$ twice per week would contain 3.7 $\mu \mathrm{g} \mathrm{Cd}$, equivalent to only $2 \%$ of the UK's tolerable weekly intake, assuming a woman weighs $60 \mathrm{~kg}$. Given the relative absorption of $\mathrm{Cd}$ of $\leq 11 \%$ [5], the contribution of any particular food item to $\mathrm{Cd}$ exposure is likely to be relatively low even if its absolute $\mathrm{Cd}$ content is high.

Similar to all leafy green and green vegetables, greater consumption of the food group all meats was associated with a reduced likelihood of $\mathrm{B}-\mathrm{Cd} \geq$ median value. Some studies have found lower $\mathrm{Cd}$ concentrations in meats than in vegetables or cereals [20,58], but offal meats, such as kidney and liver, were high in $\mathrm{Cd}$ in China [59]. This latter finding was confirmed in an exposure assessment study based on food items from 14 European countries in which offal from farmed animals contained a mean of $316 \mu \mathrm{g} \mathrm{Cd} / \mathrm{kg}$ [56], although offal would be a rarely consumed food item in most European-style diets. As noted earlier, for some individuals and population groups, meat consumption contributes little to daily $\mathrm{Cd}$ exposure because of the consumption of relatively low amounts of meat. Among 
adults from Bangladesh, for example, the estimated daily intake of $\mathrm{Cd}$ from the diet was $35 \mu \mathrm{g} / \mathrm{day}$, of which only $2 \%$ came from meats/fish, with much greater contributions from green vegetables $(35 \%)$ and from steamed rice (54\%) [20]. Similarly, among Mexican women, the contribution of meat and poultry to daily $\mathrm{Cd}$ consumption was low compared with the contribution of vegetables, grains, corn, and potatoes [23]. Among adults from northern Italy, whose average diet is about $8 \%$ meats, $10 \%$ vegetables, and $12 \%$ grains by weight, meat also contributed only a small amount (IQR $0.05-0.12 \mu \mathrm{g} /$ day) to the estimated daily Cd exposure [58]. Similarly, meat was not amongst the main contributors to dietary Cd intake in the USA [57].

It might be expected that in non-vegetarians, the high iron content of meats would result in better iron status and thus lower competition for absorptive binding sites (DMT1), resulting in lower relative $\mathrm{Cd}$ absorption, and hence lower B-Cd concentrations compared with vegetarians. In support of this, concentrations of $\mathrm{Cd}$ were significantly higher in pregnant women with low plasma ferritin at 18 weeks' gestation in a Norwegian study that included smokers and non-smokers [60]. Although we did not find any difference in B-Cd among women who reported consuming vegetarian diets compared with those who did not consume vegetarian diets, only $6 \%$ of women reported that they were vegetarian at present. In the main regression analysis, there was a suggestion of an association between the vegetarian pattern and B-Cd in the unadjusted analysis, although this was attenuated on adjustment. However, in the sensitivity analysis when values $<$ LOD were excluded, there was a strong association with the vegetarian pattern. Non-vegetarians from the Slovak Republic had B-Cd of about $25 \%$ that of vegetarians [61], although this was related to higher consumption of wholegrain products rather than vegetables. It is possible that meat consumption could be proxy for another protective factor. However, both our study and that of Krajcovicova-Kudladkova included a relatively small number of women identifying themselves as vegetarian ( $n=131$ and $n=80$, respectively), which may reduce the reliability of the results in vegetarians in both studies.

Calcium, of which milk and other dairy products are a major dietary source, is a low affinity inhibitor of DMT1 activity [62] and so a diet that is high in calcium might be expected to lower B-Cd. We found no association of B-Cd with the frequency of drinking milk or with calcium intake, although a previous study of East and South Asian women of reproductive age who had recently immigrated to Canada ( $\leq 5$ years) found that higher dairy product consumption was associated with a $14 \%$ lower risk of elevated B-Cd [63]. In addition, increasing dietary calcium and vitamin D in pregnant women also in Canada was associated with lower B-Cd [64]. The disparity between our study and these two studies could be accounted for by differences in the mean frequency of milk/dairy consumption, but comparison is difficult because of differences in the way in which variables are expressed [63] included data on the consumption of dairy items ( $52 \pm 34$ times/month); the present UK study included data specifically for milk (44\% never or rarely consumed milk, 48\% had 7-14 glasses per week, and $9 \%$ had $\geq 21$ glasses per week). The disparity in the results could also indicate differences in the frequency of consumption of other foods and food groups, which could have a secondary effect on both dietary intake and absorption of $\mathrm{Cd}$.

This study has several strengths. First, there are many advantages of using dietary patterns and food groups: (1) they take into account the effects of combinations of nutrients and foods; (2) they can provide information that is more meaningful in translation to public health messages; and (3) identification of dietary patterns by PCA is less sensitive to inaccuracy and bias in the dietary data collection than is the assessment of single nutrients [65]. Second, the study provides a valuable addition to the body of literature on $\mathrm{Cd}$ and dietary patterns by including a relatively large population of pregnant women, a vulnerable group for whom it is important to reduce $\mathrm{Cd}$ exposure to a minimum. To our knowledge, these are the most recent data on Cd exposures in pregnant women in the UK. It is likely that the prevalence of smoking will have declined, thus reducing exposures for some women. Third, in addition to dietary patterns, we were able to look further at specific foods and food groups that might have contributed to increased B-Cd (either because of being sources of cadmium, and/or because they provided nutrients that interfered with cadmium absorption or metabolism). Fourth, 
we accounted for smoking status, which is a major source of $\mathrm{Cd}$ exposure. Smoking prevalence was $29.8 \%$ prior to pregnancy and $22.2 \%$ in the first trimester. In regression models conducted on the full study sample, we added first trimester smoking status as a covariate. We also conducted sensitivity analyses by excluding first trimester smokers and then first trimester smokers plus those who smoked pre-pregnancy. Both approaches yielded similar findings.

There are also some limitations. First, the study was based in a largely urban population in the UK and may have limited generalisability to other populations of pregnant women both in the UK and in other countries. Second, Cd exposure was relatively low compared with the German recommended population upper limit [54] and this may also limit generalisability to countries with higher levels. Third, there were a large number of values for blood $\mathrm{Cd}$ concentrations below the limit of detection, making the use of the measurement as a continuous variable in linear models less robust. However, we used a well-documented means of correcting values below the limit of detection. We also modelled B-Cd as a categorical variable to minimise the influence of values $<$ LOD on the results. Fourth, blood was sampled for $\mathrm{Cd}$ analysis in the first trimester, whereas the dietary data were collected in the third trimester. The difference in timing for these assessments could make it difficult to infer causation. However, it is important to point out that B-Cd reflects $\mathrm{Cd}$ exposure over the previous 2-3 months, which could reduce the effect of the time lag between the blood and dietary data collections. In addition, both $\mathrm{B}-\mathrm{Cd}$ and urine $\mathrm{Cd}$ are stable during pregnancy [66]. Dietary patterns in pregnancy have also been shown to be stable [67], as have intakes of energy and macronutrients [68-70]. Dietary patterns specifically in pregnancy in ALSPAC are similar to those at 4 years postpartum [71]. Thus, it is likely that the data in the present study are representative of diet and biomarker concentrations throughout pregnancy, strengthening the plausibility of inference of causation. It is also possible that the consumption of vitamin and mineral supplements, which could affect $\mathrm{Cd}$ absorption, were imperfectly captured by the food frequency questionnaire. Fifth, misreporting (both under- and over-reporting) are inevitable in dietary data collection and this can undermine the validity of associations. Although there are established methods to identify misreporting of energy, those for foods and food groups are much less well understood. Sixth, the sub-sample of women included in this study were not completely identical in sociodemographic characteristics to those that were excluded. It is possible that they had higher B-Cd than those who were excluded, and this would drive the results toward the null (no associations). Finally, in those who recently stopped smoking (either before pregnancy or very early in pregnancy) and were classified as not smoking in the first trimester, it is possible that B-Cd was elevated by the effect of previous exposure through smoking. This could have the effect of causing misclassification bias. While it is known that current smokers have less healthy dietary patterns than non-smokers [72], supporting the use of current smoking as a confounder in the present analyses, little is known about the effect of smoking cessation on dietary patterns so it was not possible to take this into account in the analyses.

\section{Conclusions}

In a group of UK pregnant women, a health conscious dietary pattern (characterised by high factor loadings for salad, fruit, rice, pasta, oat and bran-based breakfast cereals, fish, pulses, fruit juices, and non-white bread) was associated with a lower likelihood of B-Cd being $\geq$ median value. There were no associations for any food or food group with B-Cd in the adjusted models, with the exception of a negative association for all leafy green and green vegetables, which appears consistent with the health conscious pattern, and with all meats. This study provides evidence to support a healthy and varied diet in pregnancy to minimise B-Cd, incorporating foods from all food groups in accordance with national recommendations.

Supplementary Materials: The following are available online at http://www.mdpi.com/2072-6643/12/4/904/s1, Table S1: Food groups and individual foods combined for the analyses, Table S2: Sensitivity analysis 1: Blood cadmium concentrations in pregnant women enrolled in ALSPAC by indicators of socio-economic positioning and lifestyle (complete case analysis excluding smokers in the first trimester, $n=1687$ ), Table S3: Sensitivity 
analysis 1: Associations of dietary patterns with blood cadmium concentrations in pregnant women enrolled in ALSPAC (complete case analysis excluding those who smoked in the first trimester, $n=1687$ ), Table S4: Sensitivity analysis 1: Associations of frequency of intakes of foods and food group with blood cadmium concentrations in pregnant women enrolled in ALSPAC (complete case analysis excluding those who smoked in the first trimester, $n$ = 1687); Table S5: Sensitivity analysis 2: Blood cadmium concentrations in pregnant women enrolled in ALSPAC by indicators of socio-economic positioning and lifestyle (complete case analysis excluding those who smoked in the first trimester and pre-pregnancy, $n=1518$ ), Table S6: Sensitivity analysis 2: Associations of dietary patterns with blood cadmium concentrations in pregnant women enrolled in ALSPAC (complete case analysis excluding current smokers and pre-pregnancy smokers, $n=1518$ ), Table S7: Sensitivity analysis 2: Associations of frequency of intakes of foods and food group with blood cadmium concentrations in pregnant women enrolled in ALSPAC (complete case analysis excluding those who smoked in the first trimester and pre-pregnancy, $n=1518$ ), Table S8: Sensitivity analysis 3: Blood cadmium concentrations in pregnant women enrolled in ALSPAC by indicators of socio-economic positioning and lifestyle (complete case analysis excluding < LOD, $n=1505$ ), Table S9: Sensitivity analysis 3: Associations of dietary patterns with blood cadmium concentrations in pregnant women enrolled in ALSPAC (complete case analysis excluding $<$ LOD, $n=1505$ ), Table S10: Blood Cd concentration in participants by vegetarian status in pregnant women enrolled in ALSPAC (in complete cases and in complete cases excluding those with values below the limit of detection), Table S11: Sensitivity analysis 3: Associations of frequency of intakes of foods and food group with blood cadmium concentrations in pregnant women enrolled in ALSPAC (complete case analysis excluding $<$ LOD, $n=1505$ )

Author Contributions: The study was conceived by K.K., K.N. and C.M.T. The analyses were carried out by R.D. and C.M.T. with advice from K.K. and K.N. The manuscript was written by C.M.T. with critical input from K.K., K.N. and R.D. All authors have read and agree to the published version of the manuscript.

Funding: The UK Medical Research Council and the Wellcome Trust (Grant ref: 102215/2/13/2) and the University of Bristol currently provide core support for ALSPAC. A comprehensive list of grants funding is available on the ALSPAC website (http://www.bristol.ac.uk/alspac/external/documents/grant-acknowledgements.pdf). This research was specifically funded by a seed grant from the Biomedical Research Unit (BRU), University of Bristol (PI: K.K.). C.M.T. was supported by a Wellcome Career Re-entry Fellowship (Grant ref: 104077/Z/14/Z) and by the Elizabeth Blackwell Institute for Health Research, University of Bristol, and the Wellcome Trust Institutional Strategic Support Fund. This publication is the work of the authors who serve as guarantors for the contents of the paper.

Acknowledgments: We are extremely grateful to all the families who took part in this study, the midwives for their help in recruiting them, and the whole ALSPAC team, which includes interviewers, computer and laboratory technicians, clerical workers, research scientists, volunteers, managers, receptionists and nurses.

Conflicts of Interest: The authors declare no conflicts of interest.

Declarations: Ethics approval and consent to participate: Ethics approval for the study was obtained from the ALSPAC Ethics and Law Committee and the Local Research Ethics Committees. Informed consent for the use of data was collected via questionnaires and clinics was obtained from participants following the recommendations of the ALSPAC Ethics and Law Committee at the time.

Availability of Data and Material: Data are available to bona fide researchers on application to the ALSPAC Executive Committee.

\section{References}

1. Gao, L.; Chang, J.; Chen, R.; Li, H.; Lu, H.; Tao, L.; Xiong, J. Comparison on cellular mechanisms of iron and cadmium accumulation in rice: Prospects in cultivating Fe-rich but Cd-free rice. Rice 2016, 9, 39. [CrossRef] [PubMed]

2. McLaughlin, M.J.; Parker, D.R.; Clarke, J.M. Metals and micronutrients-Food safety issues. Field Crops Res. 1999, 60, 143-163. [CrossRef]

3. Järup, L.; Åkesson, A. Current status of cadmium as an environmental health problem. Toxicol. Appl. Pharmacol. 2009, 238, 201-208. [CrossRef] [PubMed]

4. Taylor, C.M.; Golding, J.; Emond, A.M. Lead, cadmium and mercury levels in pregnancy: The need for international consensus on levels of concern. J. Dev. Orig. Health Dis. 2014, 5, 16-30. [CrossRef]

5. Faroon, O.; Ashizawa, A.; Wright, S.; Tucker, P.; Jenkins, K.; Ingerman, L.; Rudisill, C.; Inc, S. Toxicologial Profile for Cadmium; Agency for Toxic Substances and Disease Registry: Atlanta, GA, USA, 2012.

6. Leazer, T.M.; Liu, Y.; Klaassen, C.D. Cadmium absorption and its relationship to Divalent Metal Transporter-1 in the pregnant rat. Toxicol. Appl. Pharmacol. 2002, 185, 18-24. [CrossRef]

7. Kippler, M.; Goessler, W.; Nermell, B.; Ekström, E.C.; Lönnerdal, B.; El Arifeen, S.; Vahter, M. Factors influencing intestinal cadmium uptake in pregnant Bangladeshi women-A prospective cohort study. Environ. Res. 2009, 109, 914-921. [CrossRef] 
8. Sakamoto, M.; Chan, H.M.; Domingo, J.L.; Kubota, M.; Murata, K. Changes in body burden of mercury, lead, arsenic, cadmium and selenium in infants during early lactation in comparison with placental transfer. Ecotoxicol. Environ. Saf. 2012, 84, 179-184. [CrossRef]

9. Gundacker, C.; Hengstschläger, M. The role of the placenta in fetal exposure to heavy metals. Wien. Med. Wochenschr. 2012, 162, 201-206. [CrossRef]

10. Chen, Z.; Myers, R.; Wei, T.; Bind, E.; Kassim, P.; Wang, G.; Ji, Y.; Hong, X.; Caruso, D.; Bartell, T.; et al. Placental transfer and concentrations of cadmium, mercury, lead, and selenium in mothers, newborns, and young children. J. Expo. Sci. Environ. Epidemiol. 2014, 24, 537-544. [CrossRef]

11. Luo, Y.; McCullough, L.E.; Tzeng, J.Y.; Darrah, T.; Vengosh, A.; Maguire, R.L.; Maity, A.; Samuel-Hodge, C.; Murphy, S.K.; Mendez, M.A.; et al. Maternal blood cadmium, lead and arsenic evels, nutrient combinations, and offspring birthweight. BMC Public Health 2017, 17, 354. [CrossRef]

12. Llanos, M.N.; Ronco, A.M. Fetal growth restriction is related to placental levels of cadmium, lead and arsenic but not with antioxidant activities. Reprod. Toxicol. 2009, 27, 88-92. [CrossRef] [PubMed]

13. World Health Organization. A Recipe for Safer Food. Available online: http://www.who.int/foodsafety/ chem/TDS_recipe_2005_en.pdf (accessed on 15 January 2020).

14. Callan, A.; Hinwood, A.; Devine, A. Metals in commonly eaten groceries in Western Australia: A market basket survey and dietary assessment. Food Addit. Contam. 2014, 31, 1968-1981. [CrossRef] [PubMed]

15. Chen, M.Y.Y.; Chan, B.T.P.; Lam, C.H.; Chung, S.W.C.; Ho, Y.Y.; Xiao, Y. Dietary exposures to eight metallic contaminants of the Hong Kong adult population from a total diet study. Food Addit. Contam. 2014, 31, 1539-1549. [CrossRef] [PubMed]

16. He, P.; Lu, Y.; Liang, Y.; Chen, B.; Wu, M.; Li, S.; He, G.; Jin, T. Exposure assessment of dietary cadmium: Findings from Shanghainese over 40 years, China. BMC Public Health 2013, 13, 590. [CrossRef]

17. Schwartz, M.A.; Lindtner, O.; Blume, K.; Heinemeyer, G.; Schneider, K. Cadmium exposure from food: The German LExUKon project. Food Addit. Contam. 2014, 31, 1038-1051. [CrossRef]

18. Bannon, D.I.; Abounader, R.; Lees, P.S.; Bressler, J.P. Effect of DMT1 knockdown on iron, cadmium, and lead uptake in Caco-2 cells. Am. J. Physiol. Cell Physiol. 2003, 284, C44-C50. [CrossRef]

19. Spungen, J.H. Children's exposures to lead and cadmium: FDA Total Diet Study 2014-16. Food Addit. Contam. Part A Chem. Anal. Control Expo. Risk Assess. 2019, 1-11. [CrossRef]

20. Al-Rmalli, S.W.; Jenkins, R.O.; Haris, P.I. Dietary intake of cadmium from Bangladeshi foods. J. Food Sci. 2012, 77, T26-T33. [CrossRef]

21. Amzal, B.; Julin, B.; Vahter, M.; Wolk, A.; Johanson, G.; Akesson, A. Population toxicokinetic modeling of cadmium for health risk assessment. Environ. Health Perspect. 2009, 117, 1293-1301. [CrossRef]

22. Adams, S.V.; Quraishi, S.M.; Shafer, M.M.; Passarelli, M.N.; Freney, E.P.; Chlebowski, R.T.; Luo, J.; Meliker, J.R.; $\mathrm{Mu}$, L.; Neuhouser, M.L.; et al. Dietary cadmium exposure and risk of breast, endometrial, and ovarian cancer in the Women's Health Initiative. Environ. Health Perspect. 2014, 122, 594-600. [CrossRef]

23. Moynihan, M.; Peterson, K.E.; Cantoral, A.; Song, P.X.K.; Jones, A.; Solano-Gonzalez, M.; Meeker, J.D.; Basu, N.; Tellez-Rojo, M.M. Dietary predictors of urinary cadmium among pregnant women and children. Sci. Total Environ. 2017, 575, 1255-1262. [CrossRef] [PubMed]

24. Kim, K.; Nobles, C.; Purdue-Smithe, A.; Wactawski-Wende, J.; Pollack, A.; Freeman, J.; Alkhalaf, Z.; Andriessen, V.; Radoc, J.; Mumford, S. Food intake and blood levels of mercury, lead, and cadmium among healthy reproductive aged women (P18-024-19). Curr. Dev. Nutr. 2019, 3. [CrossRef]

25. Gunshin, H.; Mackenzie, B.; Berger, U.V.; Gunshin, Y.; Romero, M.F.; Boron, W.F.; Nussberger, S.; Gollan, J.L.; Hediger, M.A. Cloning and characterization of a mammalian proton-coupled metal-ion transporter. Nature 1997, 388, 482-488. [CrossRef] [PubMed]

26. Meltzer, H.M.; Branstæter, A.L.; Borch-Iohnsen, B.; Ellingsen, D.G.; Alexander, J.; Thomassen, Y.; Stigum, H.; Ydersbond, T.A. Low iron stores are related to higher blood lead concentrations of manganese, cobalt and cadmium in non-smoking, Norwegian women in the HUNT2 study. Environ. Res. 2010, 110, 497-504. [CrossRef]

27. Kippler, M.; Ekström, E.C.; Lönnerdal, B.; Goessler, W.; Akesson, A.; El Arifeen, S.; Persson, L.A.; Vahter, M. Influence of iron and zinc status on cadmium accumulation in Bangladeshi women. Toxicol. Appl. Pharmacol. 2007, 222, 221-226. [CrossRef] 
28. Gallagher, C.M.; Chen, J.J.; Kovach, J.S. The relationship between body iron stores and blood and urine cadmium concentrations in US never-smoking, non-pregnant women aged 20-49 years. Environ. Res. 2011, 111, 702-707. [CrossRef]

29. Meltzer, H.M.; Alexander, J.; Brantsæter, A.L.; Borch-Iohnsen, B.; Ellingsen, D.G.; Thomassen, Y.; Holmen, J.; Ydersbond, T.A. The impact of iron status and smoking on blood divalent metal concentrations in Norwegian women in the HUNT2 Study. J. Trace Elem. Med. Biol. 2016, 38, 165-173. [CrossRef]

30. Satarug, S. Dietary Cadmium intake and its effects on kidneys. Toxics 2018, 6. [CrossRef]

31. Vázquez, M.; Calatayud, M.; Jadán Piedra, C.; Chiocchietti, G.M.; Vélez, D.; Devesa, V. Toxic trace elements at gastrointestinal concentration. Food Chem. Toxicol. 2015, 86, 163-175. [CrossRef]

32. Vance, T.M.; Chun, O.K. Zinc intake is associated with lower cadmium burden in US adults. J. Nutr. 2015, 145, 2741-2748. [CrossRef]

33. Reeves, P.G.; Chaney, R.L. Bioavailability as an issue in risk assessment and management of food cadmium: A review. Sci. Total Environ. 2008, 398, 13-19. [CrossRef]

34. Fraser, A.; Macdonald-Wallis, C.; Tilling, K.; Boyd, A.; Golding, J.; Davey Smith, G.; Henderson, J.; Macleod, J.; Molloy, L.; Ness, A.; et al. Cohort profile: The Avon Longitudinal Study of Parents and Children: ALSPAC mothers cohort. Int. J. Epidemiol. 2013, 42, 97-110. [CrossRef] [PubMed]

35. Boyd, A.; Golding, J.; Macleod, J.; Lawlor, D.A.; Fraser, A.; Henderson, J.; Molloy, L.; Ness, A.; Ring, S.; Davey Smith, G. Cohort profile: The 'Children of the 90s' - The index offspring of the Avon Longitudinal Study of Parents and Children. Int. J. Epidemiol. 2013, 42, 111-127. [CrossRef] [PubMed]

36. University of Bristol. Avon Longitudinal Study of Parents and Children. Available online: www.bris.ac.uk/ alspac/ (accessed on 17 March 2020).

37. University of Bristol. Avon Longitudinal Study of Parents and Children: Explore data and samples. Available online: www.bristol.ac.uk/alspac/researchers/our-data/ (accessed on 17 March 2020).

38. Rogers, I.; Emmett, P. Diet during pregnancy in a population of pregnant women in South West England. ALSPAC Study Team. Avon Longitudinal Study of Pregnancy and Childhood. Eur. J. Clin. Nutr. 1998, 52, 246-250. [CrossRef] [PubMed]

39. Gregory, J.; Foster, K.; Tyler, H.; Wiseman, M. The Dietary and Nutritional Survey of British Adults; HMSO: London, UK, 1990.

40. Williams, C.; Birch, E.E.; Emmett, P.M.; Northstone, K.; Avon Longitudinal Study of Pregnancy and Childhood Study Team. Stereoacuity at age $3.5 \mathrm{y}$ in children born full-term is associated with prenatal and postnatal dietary factors: A report from a population-based cohort study. Am. J. Clin. Nutr. 2001, 73, 316-322. [CrossRef]

41. Northstone, K.; Emmett, P.; Rogers, I. Dietary patterns in pregnancy and associations with socio-demographic and lifestyle factors. Eur. J. Clin. Nutr. 2008, 62, 471-479. [CrossRef]

42. Taylor, C.M.; Golding, J.; Hibbeln, J.; Emond, A.M. Enviromental factors in relation to blood lead levels in pregnant women in the UK: The ALSPAC study. PLoS ONE 2013, 8, e72371. [CrossRef]

43. Centers for Disease Control and Prevention. Third National Report on Human Exposure to Environmental Chemicals; Centers for Disease Control and Prevention: Atlanta, GA, USA, 2005.

44. Hornung, R.; Reed, L.D. Estimation of average concentration in the prescence of nondetectable values. Appl. Occup. Environ. Hyg. 1990, 5, 46-51. [CrossRef]

45. Townsend, P.; Phillimore, P.; Beattie, A. Health and Deprivation: Inequality and the North; Croom Helm: London, UK, 1988.

46. Brion, M.J.; Ness, A.R.; Rogers, I.; Emmett, P.; Cribb, V.; Davey Smith, G.; Lawlor, D.A. Maternal macronutrient and energy intakes in pregnancy and offspring intake at $10 \mathrm{y}$ : Exploring parental comparisons and prenatal effects. Am. J. Clin. Nutr. 2010, 91, 748-756. [CrossRef]

47. Adams, S.V.; Newcomb, P.A. Cadmium blood and urine concentrations as measures of exposure: NHANES 1999-2010. J. Expo. Sci. Environ. Epidemiol. 2014, 24, 163-170. [CrossRef]

48. Roels, H.; Hubermont, G.; Buchet, J.P.; Lauwerys, R. Placental transfer of lead, mercury, cadmium, and carbon monoxide in women. III. Factors influencing the accumulation of heavy metals in the placenta and the relationship between metal concentration in the placenta and in maternal and cord blood. Environ. Res. 1978, 16, 236-247. [CrossRef]

49. Lauwerys, R.R.; Bernard, A.M.; Roels, H.A.; Buchet, J.P. Cadmium: Exposure markers as predictors of nephrotoxic effects. Clin. Chem. 1994, 40, 1391-1394. [CrossRef] [PubMed] 
50. Sanders, A.P.; Flood, K.; Chiang, S.; Herring, A.H.; Wolf, L.; Fry, R.C. Towards prenatal biomonitoring in North Carolina: Assessing arsenic, cadmium, mercury, and lead levels in pregnant women. PLoS ONE 2012, 7, e31354. [CrossRef] [PubMed]

51. Gerhardsson, L.; Lundh, T. Metal concentrations in blood and hair in pregnant females in southern Sweden. J. Environ. Health 2010, 72, 37-41.

52. Ebert-McNeill, A.; Clark, S.; Miller, J.; Birdsall, P.; Chandar, M.; Wu, L.; Cerny, E.; Hall, P.; Johnson, M.; Isales, C.; et al. Cadmium intake and systemic exposure in postmenopausal women and age-matched men who smoke cigarettes. Toxicol. Sci. Off. J. Soc. Toxicol. 2012. [CrossRef]

53. Menai, M.; Heude, B.; Slama, R.; Forhan, A.; Sahuquillo, J.; Charles, M.A.; Yazbeck, C. Association between maternal blood cadmium during pregnancy and birth weight and the risk of fetal growth restriction: The EDEN mother-child cohort study. Reprod. Toxicol. 2012, 34, 622-627. [CrossRef]

54. Schulz, C.; Angerer, J.; Ewers, U.; Kolossa-Gehring, M. The German Human Biomonitoring Commission. Int. J. Hyg. Environ. Health 2007, 210, 373-382. [CrossRef]

55. Ferrari, P.; Arcella, D.; Heraud, F.; Cappe, S.; Fabiansson, S. Impact of refining the assessment of dietary exposure to cadmium in the European adult population. Food Addit. Contam. Part A Chem. Anal. Control Expo. Risk Assess. 2013, 30, 687-697. [CrossRef]

56. Food Standards Agency. Total Diet Study of Metals and Other Elements in Foods; Food and Environment Research Agency: York, UK, 2015.

57. Kim, K.; Melough, M.M.; Vance, T.M.; Noh, H.; Koo, S.I.; Chun, O.K. Dietary cadmium intake and sources in the US. Nutrients 2018, 11, 2. [CrossRef]

58. Filippini, T.; Cilloni, S.; Malavolti, M.; Violi, F.; Malagoli, C.; Tesauro, M.; Bottecchi, I.; Ferrari, A.; Vescovi, L.; Vinceti, M. Dietary intake of cadmium, chromium, copper, manganese, selenium and zinc in a Northern Italy community. J. Trace Elem. Med. Biol. 2018, 50, 508-517. [CrossRef]

59. Yu, G.; Zheng, W.; Wang, W.; Dai, F.; Zhang, Z.; Yuan, Y.; Wang, Q. Health risk assessment of Chinese consumers to cadmium via dietary intake. J. Trace Elem. Med. Biol. 2017, 44, 137-145. [CrossRef] [PubMed]

60. Caspersen, I.H.; Thomsen, C.; Haug, L.S.; Knutsen, H.K.; Brantsaeter, A.L.; Papadopoulou, E.; Erlund, I.; Lundh, T.; Alexander, J.; Meltzer, H.M. Patterns and dietary determinants of essential and toxic elements in blood measured in mid-pregnancy: The Norwegian Environmental Biobank. Sci. Total Environ. 2019, 671, 299-308. [CrossRef] [PubMed]

61. Krajcovicova-Kudladkova, M.; Ursinyova, M.; Masanova, V.; Bederova, A.; Valachovicova, M. Cadmium blood concentrations in relation to nutrition. Cent. Eur. J. Public Health 2006, 14, 126-129. [CrossRef] [PubMed]

62. Shawki, A.; Mackenzie, B. Interaction of calcium with the human divalent metal-ion transporter-1. Biochem. Biophys. Res. Commun. 2010, 393, 471-475. [CrossRef]

63. Dix-Cooper, L.; Kosatsky, T. Blood mercury, lead and cadmium levels and determinants of exposure among newcomer South and East Asian women of reproductive age living in Vancouver, Canada. Sci. Total Environ. 2018, 619-620, 1409-1419. [CrossRef]

64. Arbuckle, T.E.; Liang, C.L.; Morisset, A.S.; Fisher, M.; Weiler, H.; Cirtiu, C.M.; Legrand, M.; Davis, K.; Ettinger, A.S.; Fraser, W.D.; et al. Maternal and fetal exposure to cadmium, lead, manganese and mercury: The MIREC study. Chemosphere 2016, 163, 270-282. [CrossRef]

65. Newby, P.K.; Tucker, K.L. Empirically derived eating patterns using factor or cluster analysis: A review. Nutr. Rev. 2004, 62, 177-203. [CrossRef]

66. Bocca, B.; Ruggieri, F.; Pino, A.; Rovira, J.; Calamandrei, G.; Martinez, M.A.; Domingo, J.L.; Alimonti, A.; Schuhmacher, M. Human biomonitoring to evaluate exposure to toxic and essential trace elements during pregnancy. Part A. concentrations in maternal blood, urine and cord blood. Environ. Res. 2019, 177, 108599. [CrossRef]

67. McGowan, C.A.; McAuliffe, F.M. Maternal dietary patterns and associated nutrient intakes during each trimester of pregnancy. Public Health Nutr. 2013, 16, 97-107. [CrossRef]

68. Savard, C.; Lemieux, S.; Weisnagel, S.J.; Fontaine-Bisson, B.; Gagnon, C.; Robitaille, J.; Morisset, A.S. Trimester-specific dietary intakes in a sample of French-Canadian pregnant women in comparison with national nutritional guidelines. Nutrients 2018, 10. [CrossRef]

69. Kopp-Hoolihan, L.E.; van Loan, M.D.; Wong, W.W.; King, J.C. Longitudinal assessment of energy balance in well-nourished, pregnant women. Am. J. Clin. Nutr. 1999, 69, 697-704. [CrossRef] [PubMed] 
70. Kubota, K.; Itoh, H.; Tasaka, M.; Naito, H.; Fukuoka, Y.; Muramatsu Kato, K.; Kohmura, Y.K.; Sugihara, K.; Kanayama, N.; Hamamatsu Birth Cohort Study Team. Changes of maternal dietary intake, bodyweight and fetal growth throughout pregnancy in pregnant Japanese women. J. Obstet. Gynaecol. Res. 2013, 39, 1383-1390. [CrossRef] [PubMed]

71. Northstone, K.; Emmett, P.M. A comparison of methods to assess changes in dietary patterns from pregnancy to 4 years post-partum obtained using principal components analysis. Br. J. Nutr. 2008, 99, 1099-1106. [CrossRef] [PubMed]

72. Suh, S.Y.; Lee, J.H.; Park, S.S.; Seo, A.R.; Ahn, H.Y.; Bae, W.K.; Lee, Y.J.; Yim, E. Less healthy dietary pattern is associated with smoking in Korean men according to nationally representative data. J. Korean Med. Sci. 2013, 28, 869-875. [CrossRef] [PubMed]

C 2020 by the authors. Licensee MDPI, Basel, Switzerland. This article is an open access article distributed under the terms and conditions of the Creative Commons Attribution (CC BY) license (http://creativecommons.org/licenses/by/4.0/). 